\section{Commentary: The complete cardiothoracic surgeon: Give me a rib plate}

\author{
Richard Lazzaro, MD, FACS, and Byron Patton, MD
}

In the current issue of the Journal, Nakamoto and colleagues ${ }^{1}$ describe the presentation and management of a patient who developed shoulder pain and discomfort with abduction 6 years after blunt trauma with multiple rib fractures, which were treated conservatively. Based on presentation, physical findings, and radiographic findings, snapping scapula syndrome was diagnosed. Surgical intervention and rib plating were performed, with resolution of symptoms. ${ }^{1}$

Rib fractures occur in approximately $10 \%$ of trauma patients and $30 \%$ of patients with severe chest trauma. ${ }^{2,3}$ The 2017 practice guideline from the Eastern Association for the Surgery of Trauma recommends operative fixation "in adult patients with flail chest after blunt trauma ... compared to nonoperative management, to decrease mortality; shorten DMV, ICU LOS, and hospital LOS; incidence of pneumonia, and need for tracheostomy." " Indications listed by Mitchell ${ }^{4}$ in a comprehensive review of rib stabilization in blunt chest trauma are "acute respiratory failure attributable to fractures and refractory to medical management, acute pain attributable to fractures and refractory to medical management, anticipated chronic pain/impaired pulmonary mechanics (anatomic considerations), flail chest: 3 or more contiguous ribs with $2+$ fractures, $\geq 3$ severely displaced, bicortical fractures, loss of $\geq 30 \%$ chest wall volume, exposure required for additional thoracic procedures."

From the Department of Cardiothoracic Surgery, Lenox Hill Hospital, Northwell Health, Donald and Barbara Zucker School of Medicine at Hofstra/Northwell, New York, NY.

Disclosures: The authors reported no conflicts of interest.

The Journal policy requires editors and reviewers to disclose conflicts of interest and to decline handling or reviewing manuscripts for which they may have a conflict of interest. The editors and reviewers of this article have no conflicts of interest.

Received for publication May 31, 2020; revisions received May 31, 2020; accepted for publication June 6, 2020; available ahead of print June 14, 2020.

Address for reprints: Richard Lazzaro, MD, FACS, Department of Cardiothoracic Surgery, Lenox Hill Hospital, Northwell Health, Donald and Barbara Zucker School of Medicine at Hofstra/Northwell, 130 East 77th St, New York, NY 10075 (E-mail: rlazzaro@northwell.edu).

JTCVS Techniques 2020;3:378-9

2666-2507

Copyright $@ 2020$ The Authors. Published by Elsevier Inc. on behalf of The American Association for Thoracic Surgery. This is an open access article under the CC BY-NCND license (http://creativecommons.org/licenses/by-nc-nd/4.0/).

https://doi.org/10.1016/j.xjtc.2020.06.004

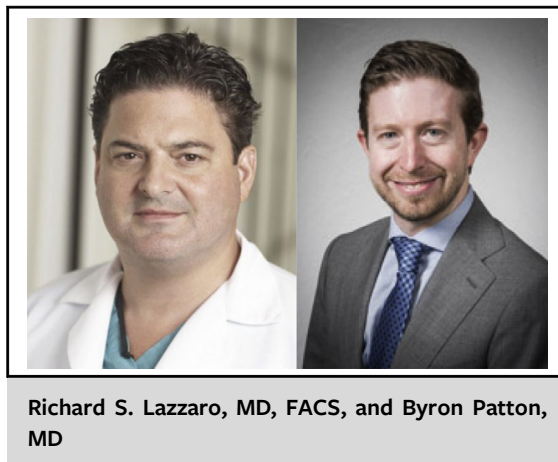

CENTRAL MESSAGE

Rib fractures secondary to blunt chest trauma are a cause of acute and chronic morbidity. The time to consider expanded indications for rib fixation is now.

Long-term follow-up after rib fixation for flail chest as well as multiple rib fractures, by Beks and colleagues, ${ }^{5}$ reports that one half of the patients will experience implantrelated pain and about $10 \%$ will require implant removal. In a cohort of 78 patients with rib fractures identified on initial computed tomography scan and followed up with subsequent computed tomography imaging (median time 6 days), Bauman and colleagues ${ }^{6}$ noted that rib fracture displacement worsened over time.

Operative intervention healed the patient of Nakamoto and colleagues, which brings to a mind a quote from $\mathrm{Dr}$ Frank Spencer, "When a patient gets well his doctor 'feels' good-a personal warm glow that tells him once again what being a doctor is. This pleasure never dulls with age or time, but remains vital and strong after decades of practice. 'Becoming a doctor' is acquiring this ability to help a sick person get better. It is one of the most precious skills one can acquire in a lifetime." "I am also reminded of Dr Joseph I. Miller Jr, who discussed "Why I Chose Cardiothoracic Surgery." ${ }^{\prime}$ Dr Miller listed 13 qualities of the complete cardiothoracic surgeon, which he had discussed during his presidential address, "The Complete Cardiothoracic Surgeon: Qualities of Excellence" at the Southern Thoracic Surgical Association in 2003. Five of those 13 qualities of the complete cardiothoracic surgeon are listed to follow:

1. "An excellent technical surgeon with good judgment

2. An excellent radiologist

3. Have knowledge of new surgical technology

4. Be adaptable 
5. Have a historical knowledge of the specialty."

Nakamoto and colleagues demonstrated that patient evaluation with radiology guidance resulted in sound patient selection for surgery, with a satisfactory outcome. Perhaps the time has come to evaluate patients with rib fracture for fixation in a prospective fashion to become that complete cardiothoracic surgeon. Let's have some ribs.

\section{References}

1. Nakamoto K, Sumiura S, Hashiyada H, Kiya S. Snapping scapula due to traumatic costal fractures: a case report. J Thorac Cardiovasc Surg Tech. 2020;3:375-7.

2. Ziegler DW, Agarwal NN. The morbidity and mortality of rib fractures. J Trauma. 1994;37:975.
3. Kasotakis G, Hasenboehler EA, Streib EW, Patel N, Patel MB, Alarcon L, et al Operative fixation of rib fractures after blunt trauma: a practice management guideline from the Eastern Association for the Surgery of Trauma. J Trauma Acute Care Surg. 2017;82:618-26.

4. Mitchell JD. Blunt chest trauma: is there a place for rib stabilization? J Thorac Dis. 2017;9(suppl 3):S211-7.

5. Beks RB, de Jong MB, Houwert RM, Sweet AAR, De Bruin IGJM, Govaert GAM, et al. Long-term follow-up after rib fixation for flail chest and multiple rib fractures. Eur J Trauma Emerg Surg. 2019;45:645-54.

6. Bauman ZM, Grams B, Yanala U, Shostrom V, Waibel B, Evans CH, et al. Rib fracture displacement worsens over time. Eur J Trauma Emerg Surg. March 27, 2020 [Epub ahead of print].

7. American College of Surgeons. Why do surgeons become surgeons? Available at: https://www.facs.org/education/resources/medical-students/faq/why. Accessed May 25, 2020.

8. Miller JI Jr. Why I chose cardiothoracic surgery. Available at: https://www.ctsnet org/sections/residents/featresarticles/article-17. Accessed May 25, 2020. 